\title{
Definitive palliation with cavopulmonary or aortopulmonary shunts for adults with single ventricle physiology
}

\author{
M A Gatzoulis, M-D Munk, W G Williams, G D Webb
}

\begin{abstract}
Objective-To compare the relative merits of cavopulmonary or aortopulmonary shunts, or both, as definitive non-Fontan palliations for patients with single ventricle physiology.

Design-Clinical data, ECG, echocardiographic data, surgical records, and available postmortem material were reviewed in all patients with single ventricle physiology identified from the University of Toronto Congenital Cardiac Centre for Adults (UTCCCA) database who had not undergone a Fontan operation. Current status of patients was assessed from clinic reviews and patient contact. Two groups of patients were identified: those with cavopulmonary shunt (group $1, \mathrm{n}=35$ ); and those with aortopulmonary shunt(s) only (group 2, $\mathrm{n}=15$ ).

Results-50 adults ( 21 male/29 female) who underwent the last palliation at a median age of 11 years (range 1 day to 53 years) were identified. During a mean (SD) follow up of 13.0 (6.2) years at the UTCCCA, 19 patients died. Survival is $89.4 \%$ and $51.9 \%$ at 10 and 20 years, respectively, from the time patients were first seen at UTCCCA, with no differences between the groups. Most recent New York Heart Association (NYHA) classification was I-II in 21 patients, III in 25, and IV in four patients; mean haemoglobin was 190 (28) g/l, and oxygen saturation was 82 (4)\%, with no group differences. Arrhythmia developed in 25 patients (atrial flutter/fibrillation in 20 and/or sustained ventricular tachycardia in 11). Atrial flutter/fibrillation was more common in patients in group 2, who also showed a greater decline in ventricular function with time. Age at last palliation, cardiothoracic ratio, and inclusion in group 2 were predictive of atrial flutter/fibrillation, poor ventricular function predictive of ventricular tachycardia, NYHA class > III, and prior ventricular tachycardia predictive of death.

Conclusions-Cavopulmonary or aortopulmonary shunts, or both, provide sustained palliation for selected patients with single ventricle physiology. Survival for both compares favourably with published Fontan series. Compared to aortopulmonary shunts, cavopulmonary shunts convey a beneficial long term effect on ventricular function. Arrhythmia is a major cause of late morbidity in these patients, relating to both ventricular dysfunction and death. Onset of sustained ventricular tachycardia is an ominous sign.

(Heart 2000;83:51-57)
\end{abstract}

Keywords: congenital heart defects; cavopulmonary shunt; cyanosis; Fontan procedure

Cavopulmonary ${ }^{12}$ and aortopulmonary shunts ${ }^{3-5}$ have long been available as palliative procedures for patients with single ventricle physiology - that is, patients unsuitable for biventricular repair. Since the introduction of the Fontan procedure, ${ }^{6}$ cavopulmonary and aortopulmonary shunts have been mainly used for early relief of cyanosis as part of a staged protocol in patients with single ventricle physiology..$^{7-9}$ A more definitive palliation in the form of one of the Fontan modifications ${ }^{10-12}$ would usually follow. There are patients, however, who are high risk Fontan candidates, ${ }^{13}$ and for these patients cavopulmonary and aortopulmonary shunts may be used as long term palliation. ${ }^{14}$

Whereas both the cavopulmonary and aortopulmonary shunts can provide acceptable levels of oxygen saturation in children and adults with cyanotic congenital heart disease, a number of differences in terms of indications, feasibility, and long term outcome between the two may exist. The main haemodynamic advantage of the cavopulmonary shunt compared to aortopulmonary shunts is volume off loading of the "single" ventricle. ${ }^{15}{ }^{16}$ Ventricular off loading following construction of a cavopulmonary shunt, in turn, may confer better long term preservation of ventricular function, and perhaps a better overall outcome in these patients compared to those who have been palliated with aortopulmonary shunts only. However, this hypothesis had not been clinically tested before.

Our study compares the relative merits of cavopulmonary and aortopulmonary shunts and reports on the overall outcome of adult patients palliated for single ventricle physiology who have not undergone a Fontan completion.

\section{Methods}

The study group comprised all patients from the University of Toronto Congenital Cardiac Centre for Adults (UTCCCA) with single ventricle physiology who: (a) have been palliated with a cavopulmonary shunt, or one or more aortopulmonary shunts, or both; and (b) have not undergone a Fontan modification. Patients were identified from the UTCCCA database. Hospital records were reviewed for clinical, morphological, and haemodynamic details. Additional information, when required, was 
Table 1 Baseline characteristics

\begin{tabular}{|c|c|c|c|}
\hline & $\begin{array}{l}\text { Cavopulmonary } \\
\text { shunt }(n=35)\end{array}$ & $\begin{array}{l}\text { Aortopulmonary } \\
\text { shunt (s) only } \\
(n=15)\end{array}$ & $p$ Value \\
\hline \multicolumn{4}{|l|}{ Demographics, diagnosis } \\
\hline Age at last palliation (years) & $12(1-35)$ & 1 day to 53 & 0.980 \\
\hline Male & $13(37 \%)$ & $8(33.3 \%)$ & 0.233 \\
\hline \multicolumn{4}{|l|}{ Diagnosis } \\
\hline Double inlet ventricle & $11(31 \%)$ & $3(20 \%)$ & \\
\hline Triscuspid atresia & $13(37 \%)$ & $8(53 \%)$ & \\
\hline Isomeric atrial appendages & $4(11 \%)$ & $2(13 \%)$ & \\
\hline Pulmonary atresia/intact septum & $3(9 \%)$ & $1(7 \%)$ & \\
\hline Other hypoplastic ventricle ${ }^{\star}$ & $4(11 \%)$ & $1(7 \%)$ & \\
\hline Left ventricular morphology & $32(91 \%)$ & $13(87 \%)$ & 0.607 \\
\hline Antegrade flow (ventricle to pulmonary artery) & $19 \dagger$ & 9 & 0.933 \\
\hline Previous palliation, once & $24(67 \%)$ & $9(60 \%)$ & 0.558 \\
\hline Previous palliation, twice & $4(11 \%)$ & $2(13 \%)$ & 0.849 \\
\hline \multicolumn{4}{|l|}{ Preoperative class } \\
\hline NYHA class & & & 0.098 \\
\hline I & $1(3 \%)$ & $1(7 \%)$ & \\
\hline II & $17(49 \%)$ & $3(20 \%)$ & \\
\hline III & $16(46 \%)$ & $11(73 \%)$ & \\
\hline IV & $1(3 \%)$ & - & \\
\hline Mean (SD) haemoglobin $(\mathrm{g} / \mathrm{l})$ & $187(29)$ & $184(43)$ & 0.850 \\
\hline Mean (SD) oxygen saturation (\%) & $78.6(8.3)$ & $82.1(6.4)$ & 0.202 \\
\hline Mean (SD) pulmonary artery pressure $(\mathrm{mm} \mathrm{Hg})$ & $14.4(4.1)$ & $22.1(13.4)$ & 0.013 \\
\hline \multicolumn{4}{|c|}{ Reasons for not performing a Fontan modification (at last palliation) } \\
\hline Hypoplastic/distorted pulmonary arteries & $13(37 \%)$ & $7(47 \%)$ & \\
\hline Impaired ventricular function $(\geqslant$ III) & $10(29 \%)$ & - & \\
\hline Atrioventricular valve regurgitation ( $\geqslant$ II) & $3(9 \%)$ & - & \\
\hline Mean pulmonary artery pressure $>18 \mathrm{~mm} \mathrm{Hg}$ & - & $4(27 \%)$ & \\
\hline Complex pulmonary venous return & $3(9 \%)$ & $1(7 \%)$ & \\
\hline Age $<2$ years & $1(3 \%)$ & $2(13 \%)$ & \\
\hline High risk candidate/patient declined $\ddagger$ & $5(14 \%)$ & $1(7 \%)$ & \\
\hline
\end{tabular}

\%) Percentage per group.

*Associated with straddling, ebsteinoid or atretic atrioventricular valve.

†Including all 11 patients who had a cavopulmonary shunt only.

Combination of more than one risk factor ${ }^{13}$ for a Fontan procedure and patient or family preference to proceed with a lower risk palliation.

Table 2 Surgical details

\begin{tabular}{|c|c|c|c|}
\hline & $\begin{array}{l}\text { Cavopulmonary } \\
\text { shunt }(n=35)\end{array}$ & $\begin{array}{l}\text { Aortopulmonary } \\
\text { shunt }(s) \text { only } \\
(n=15)\end{array}$ & $p$ Value \\
\hline First palliation, number of patients & 15 & 18 & \\
\hline Age at first palliation & $\begin{array}{l}1 \text { year } \\
\text { (1 day }-5 \text { years })\end{array}$ & $\begin{array}{l}6 \text { months } \\
\text { (1 day-13 years) }\end{array}$ & 0.199 \\
\hline Type of first palliation & & & 0.053 \\
\hline Blalock-Taussing shunt & 4 & 3 & \\
\hline Potts shunt & 8 & 5 & \\
\hline Waterston shunt & 3 & 1 & \\
\hline Cavopulmonary shunt, end to end & 9 & NA & \\
\hline Pulmonary artery banding & 5 & 2 & 0.613 \\
\hline Second palliation, number of patients & 2 & 4 & 0.849 \\
\hline Age at second palliation (years) & $4.5(2.6)$ & $10.0(1.4)$ & 0.057 \\
\hline Type of last palliation & & & $\begin{array}{l}< \\
0.001\end{array}$ \\
\hline Blalock-Taussing shunt & 7 & 10 & \\
\hline Waterston shunt & - & 2 & \\
\hline Interposition graft (aortopulmonary) & 2 & 3 & \\
\hline Cavopulmonary shunt, end to end & 23 & NA & \\
\hline Cavopulmonary shunt, bidirectional & 3 & NA & \\
\hline Follow up surgery & & & \\
\hline Axillary arteriovenous fistula & 5 & NA & \\
\hline Years from last palliation & $14.4(4.3)$ & NA & \\
\hline Heart transplantation & 4 & - & 0.172 \\
\hline Years from last palliation & $13.0(5.6)$ & - & - \\
\hline
\end{tabular}

NA, not applicable.

obtained from the Hospital for Sick Children, Toronto, where most patients were treated before transfer to UTCCCA. Patients were assigned to one of five diagnostic categories shown in table 1 . Data from cardiac catheterisations before the last palliation were reviewed and the mean pulmonary artery pressure recorded. Pulmonary arteries were assessed for significant distortion, defined as disconnected pulmonary arteries or branch pulmonary artery stenoses requiring major reconstruction, and for hypoplasia $\left(\mathrm{McGoon}^{17}\right.$ ratio < 1.5$)$. Reasons for not performing a Fontan modification $^{13}$ at the last palliation are presented in table 1 . Previous palliations enhancing pulmonary blood flow and/or the presence of antegrade ventricular flow to the main pulmonary artery ${ }^{18}$ were also recorded. Surgical history, including type of the last and previous palliations and additional surgical procedures, such as pulmonary artery banding, was obtained from operative notes in all patients (table 2).

The follow up status of patients was determined from hospital records and UTCCCA clinic visits. If a clinic visit had not been performed within six months of the December 1998 inclusion date, contact with the primary physician or patient, or both, was made. Death and arrhythmia, in the form of sustained atrial flutter/fibrillation or sustained ventricular tachycardia were the primary end points of the study. The mode of death and available postmortem reports were reviewed and recorded in all patients. The arrhythmia group comprised patients presenting with either sustained atrial flutter/fibrillation (paroxysmal or chronic) or sustained ventricular tachycardia documented by a 12 lead ECG, Holter recording, or rhythm strip tracings.

Other events, such as reoperations, phlebotomies, and systemic thromboembolism, were also recorded.

Oxygen saturation was measured in room air with finger pulse oximetry following a resting period of five minutes. ECGs and chest radiographs were obtained during clinic reviews. Echocardiograms including colour Doppler and $\mathrm{M}$ mode recordings were performed as part of the periodic UTCCCA clinic assessment of these patients. Subaortic stenosis (peak instantaneous Doppler gradient at rest $>20 \mathrm{~mm} \mathrm{Hg}$ ) was recorded when present. Systolic ventricular function was graded as I (normal, ejection fraction $>60 \%$ ), II (mild dysfunction, ejection fraction $40-59 \%$ ), III (moderate dysfunction, ejection fraction 20$39 \%$ ), and IV (severe dysfunction, ejection fraction <20\%). Systemic atrioventricular valve regurgitation was classified as I = absent/ trivial, $\quad$ II = mild, $\quad$ III = moderate, $\quad$ and IV = severe, according to standard techniques. ${ }^{19}$ Postoperative cardiac catheterisation was performed when clinically indicated.

For the purpose of the statistical analysis, latest follow up status was assessed between July and December 1998 or at the last clinic review before the occurrence of arrhythmia, death, or heart transplantation. We classified patients into two groups based on the presence or not of a cavopulmonary shunt: (1) patients with a cavopulmonary shunt (combined or not with an aortopulmonary shunt); and (2) the remainder who had aortopulmonary shunt(s) only.

\section{DATA ANALYSIS}

Data analysis was performed using SPSS for Windows software (Version 7.5, Chicago). Descriptive data for continuous variables are presented as mean (SD) or median with range when appropriate. $\chi^{2}$ or Fisher's exact tests were used to compare discrete variables. 
Table 3 Follow up data

\begin{tabular}{|c|c|c|c|}
\hline & $\begin{array}{l}\text { Cavopulmonary } \\
\text { shunt }(n=35)\end{array}$ & $\begin{array}{l}\text { Aortopulmonary } \\
\text { shunt }(s) \text { only } \\
(n=15)\end{array}$ & $p$ Value \\
\hline Mean (SD) time from last palliation (years) & $19.3(7.6)$ & $17.9(7.0)$ & 0.546 \\
\hline Deaths & 13 & 6 & 0.849 \\
\hline Mode of death & & & 0.086 \\
\hline Sudden cardiac & $4(31 \%)$ & $6(100 \%)$ & \\
\hline Heart failure & $4(31 \%)$ & - & \\
\hline Cardiopulmonary, other & $3(23 \%)^{\star}+\ddagger$ & - & \\
\hline Non-cardiac & $2(15 \%)$ & - & \\
\hline Latest NYHA & & & 0.253 \\
\hline I & $4(11 \%)$ & - & \\
\hline II & $11(31 \%)$ & $6(40 \%)$ & \\
\hline III & $16(46 \%)$ & $9(60 \%)$ & \\
\hline IV & $4(11 \%)$ & - & \\
\hline Phlebotomies & 15 & 4 & 0.248 \\
\hline Systemic thromboembolic events & 5 & 4 & 0.319 \\
\hline Mean (SD) latest haemoglobin (g/l) & $187(28)$ & $197(25)$ & 0.242 \\
\hline Mean (SD) latest oxygen saturation (\%) & $82(5)$ & $83(4)$ & 0.490 \\
\hline Mean (SD) cardiothoracic ratio & $0.57(0.08)$ & $0.62(0.06)$ & 0.049 \\
\hline Subaortic stenosis (resting gradient $>20 \mathrm{~mm} \mathrm{Hg}$ ) & 2 & 1 & 0.897 \\
\hline Systemic ventricular function & & & 0.312 \\
\hline $\mathrm{I}$ & $5(14 \%)$ & - & \\
\hline II & $15(43 \%)$ & $5(33 \%)$ & \\
\hline III & $12(24 \%)$ & $8(53 \%)$ & \\
\hline IV & $3(9 \%)$ & $2(13 \%)$ & \\
\hline Systemic atrioventricular valve regurgitation & & & 0.180 \\
\hline $\mathrm{I}$ & $13(37 \%)$ & - & \\
\hline II & $14(40 \%)$ & $10(67 \%)$ & \\
\hline III & $5(14 \%)$ & $4(20 \%)$ & \\
\hline IV & $3(9 \%)$ & $2(13 \%)$ & \\
\hline Pulmonary arteriovenous malformations & $5 \rrbracket$ & - & 0.111 \\
\hline Sustained atrial flutter/fibrillation & 11 & 9 & 0.002 \\
\hline Sustained ventricular tachycardia & 7 & 4 & 0.713 \\
\hline
\end{tabular}

Continuous data were analysed using the two sample $t$ test or the Wilcoxon rank sum test when appropriate. The probability of survival and remaining free from atrial flutter/ fibrillation and sustained ventricular tachycardia since the first clinic visit at UTCCCA was estimated by the Kaplan-Meier method, and was compared between the two groups. The significance of each comparison was calculated with a one sample log rank test. ${ }^{20}$ Univariate analysis of predictors of atrial flutter/ fibrillation, ventricular tachycardia, and sudden death was performed using Cox's proportional hazard model. ${ }^{21}$ Predictors for each outcome (atrial flutter/fibrillation, ventricular tachycardia, and death) were analysed separately. Univariate predictors with a significance level of $p<0.10$ were entered into a multivariate Cox's proportional hazard model using a backwards elimination algorithm. The level of significance for the multivariate model was set at $\mathrm{p}=0.05$.

\section{Results}

PATIENTS

Fifty adult patients (21 male/29 female) who underwent a cavopulmonary (26 patients; end to end (or classic Glenn) in 23 and bidirectional in three) or aortopulmonary shunt (24 patients) and not a Fontan modification as their last palliation for single ventricle physiology were identified. Their mean age at palliation was $12.6(10.0)$ years (median 11 years, range 1 day to 53 years) and the total follow up time was 18.9 (7.3) years. Thirty three $(66 \%)$ of them had one or more previous palliations, enhancing pulmonary blood flow to

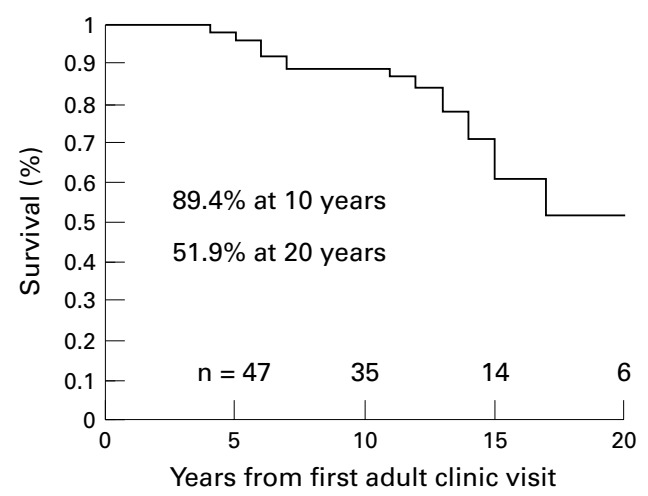

Figure 1 Kaplan-Meier survival curve for 50 patients with single ventricle physiology palliated with a cavopulmonary shunt, aortopulmonary shunt, or both, and not a Fontan modification. Time indicates years from admission to the adult clinic. Thirty three patients underwent the last palliation at a mean of 8.4 (4.4) years before their first visit to the adult clinic.

the contralateral lung; previous palliation was an end to end cavopulmonary shunt in nine of them, resulting in a total of 35 of the 50 patients palliated with a cavopulmonary shunt (group 1). For the remaining 15 patients augmentation of pulmonary blood flow was achieved with aortopulmonary shunts only (group 2) (table 1). In addition, 28 patients $(56 \%)$ had antegrade flow from the ventricle to the main pulmonary artery at the time of the last palliation.

Surgery (table 2) took place at the Toronto Hospital (following a UTCCCA consultation) in 17 patients. There was no early mortality in this subset. Thirty patients had their last (and previous) palliation at the Hospital for Sick Children, Toronto, and the remaining three patients in other institutions before their transfer to our service. Patients had been referred to the UTCCCA between 16-18 years of age, where they have been followed up since.

\section{FOLLOW UP STATUS}

During a mean of 13.0 (6.2) years from the first clinic visit at UTCCCA, $19(38 \%)$ of the 50 patients died (table 3 ). Death occurred at a mean age of $31.7(8.0)$ years at $19.6(6.8)$ years from the last palliation. Ten $(53 \%)$ patients died suddenly, four $(21 \%)$ from heart failure, three $(16 \%)$ from other cardiopulmonary causes, one from lung cancer, and one in a road traffic accident. Survival was $89.4 \%$ and $51.9 \%$ at 10 and 20 years, respectively, from the first UTCCCA clinic visit (fig 1), with no difference between the two groups. At the latest follow up, $21(42 \%)$ of the patients were in New York Heart Association (NYHA) class I-II, 25 $(50 \%)$ in class III, and four patients $(8 \%)$ in class IV. There were no differences between haemoglobin and oxygen saturation between the two groups. Oxygen saturation in room air ranged between $71-91 \%$ (mean 82 (4)\%). Pulmonary arteriovenous malformations were present in five patients, all of whom had an end to end cavopulmonary shunt. In two patients the fistulae were considered severe enough to warrant transcatheter embolisation, which resulted in improvement in cyanosis in both. The five patients who developed pulmonary 


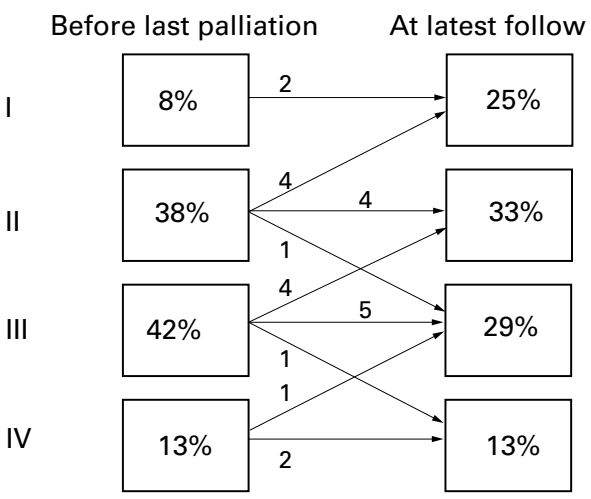

Figure 2 Systemic ventricular function assessed echocardiographically in 24 patients who underwent a cavopulmonary shunt as their last palliation, showing relative preservation of function over a mean period of 12.0 (5.6) years.

arteriovenous malformations were significantly younger (3.7 (2.1) years) at the time of Glenn construction, compared to the remaining 27 patients who also had an end to end cavopulmonary shunt (at mean age 8.3 (2.9) years, $\mathrm{p}<0.05$ ) but no evidence of pulmonary arteriovenous fistulae formation. There was no difference in length of follow up between patients who developed pulmonary arteriovenous malformations and those who did not.

Cardiothoracic ratio was significantly greater in the aortopulmonary shunt group. Echocardiographic assessment of systemic ventricular function before the last palliation and at the latest follow up showed a decline in ventricular function in the second group, whereas ventricular function remained relatively stable in the first group (fig 2).

\section{ARRHYTHMIA}

Twenty six (52\%) of the 50 patients were identified as having one or more episodes of documented sustained atrial flutter/fibrillation (20 patients) and/or ventricular tachycardia (11 patients) since they were first seen at UTCCCA. Three of the 26 patients presented with syncope requiring cardiopulmonary resuscitation whereas the remainder presented with palpitations or presyncope, or both. Twenty patients were treated with amiodarone, and the remaining six patients (with atrial flutter/fibrillation) were treated with digoxin. Eighteen patients were anticoagulated with coumadin. In addition, two patients underwent implantation of an epicardial antitachycardia pacemaker system.

Atrial flutter/fibrillation

Freedom from atrial flutter/fibrillation at 10 years was $85.3 \%$ and $65 \%$ for the first and second groups, respectively. Thus, the probability of remaining free from atrial flutter/fibrillation was significantly lower in patients who had aortopulmonary shunt(s) only (log rank test, $\mathrm{p}=0.04$, fig 3 ). Five of the 20 patients with atrial flutter/fibrillation subsequently developed sustained ventricular tachycardia at a mean of 2.6 (1.3) years from initial presentation with arrhythmia. Of the remaining 15 patients, four died (sudden cardiac death in

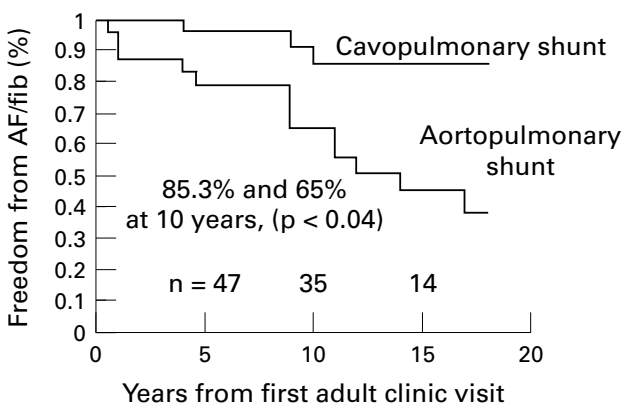

Figure 3 Freedom from atrial flutter/fibrillation ( $A F / f i b)$ for the 35 patients palliated with a cavopulmonary shunt versus the 15 patients palliated with aortopulmonary shunts only; atrial flutter/fibrillation was more common in patients with aortopulmonary shunts only $(p<0.04, \log$ rank). Time indicates years from admission to the adult clinic. Thirty three patients underwent the last palliation at a mean of 8.4 (4.4) years before their first visit to the adult clinic.

two, heart failure death in two) at a mean of 5.8 (3.0) years from the first documented arrhythmia.

Sustained ventricular tachycardia

Freedom from sustained ventricular tachycardia at 10 and 20 years was $90.7 \%$ and $73.2 \%$, respectively, with no difference between the two groups. Nine of the 11 patients with documented ventricular tachycardia died at a mean of $1.4(0.8)$ years from their first episode of ventricular tachycardia, six of them suddenly.

\section{REOPERATIONS}

During follow up at the UTCCCA, a Fontan modification was considered but thought to be of high risk and not performed in nine $(18 \%)$ of the 50 patients.

Five patients had an axillary arteriovenous fistula $^{22}$ resulting in improvement of oxygen saturation by a mean of $5.7(1.7) \%$.

Four patients who were in NYHA class IV were placed on the active heart transplantation list at a mean of 18.0 (9.6) years from last palliation. Two of them underwent successful heart transplantation and three to four years later are in NYHA class I, one patient died intraoperatively during transplantation from myocardial standstill, and the fourth patient died while on the waiting list.

Nineteen $(38 \%)$ patients underwent phlebotomies for symptoms of hyperviscosity. Nine (18\%) patients experienced one or more systemic thromboembolic events, including one who died from stroke. There was a relation between patients who underwent phlebotomies and those who experienced systemic thromboembolic events $\left(\chi^{2}\right.$ test, $\left.\mathrm{p}<0.01\right)$.

No patient developed protein losing enteropathy.

PREDICTORS OF ARRHYTHMIA AND DEATH

Multivariate analysis showed: (1) age at last palliation, palliation with aortopulmonary shunts only, and late follow up cardiothoracic ratio to be predictive of atrial flutter/fibrillation; (2) moderate or severe systolic ventricular dysfunction to be predictive of ventricular tachycardia; and (3) NYHA class III or IV and a prior episode of sustained ventricular tachycardia to 
Table 4 Predictors of atrial flutter/fibrillation, ventricular tachycardia, and death in patients with single ventricle physiology palliated with a cavopulmonary shunt or aortopulmonary shunt

\begin{tabular}{|c|c|c|c|}
\hline & Atrial flutter/fibrillation & Ventricular tachycardia & Death \\
\hline \multicolumn{4}{|c|}{ Multivariate analysis ( $p$ value (risk ratio, $95 \%$ confidence limit)) } \\
\hline Age at last palliation, per year & $0.001(1.09,1.03$ to 1.16$)$ & - & _- \\
\hline Aortopulmonary shunt(s) only & $0.008(4.5,1.5$ to 13.8$)$ & _- & - \\
\hline Follow up cardiothoracic ratio & $0.014(3.46,1.49$ to 8.03$)$ & _- & _- \\
\hline Follow up ventricular function & - & $0.024(3.3,1.8$ to 9.3$)$ & _- \\
\hline Follow up NYHA class $\geqslant$ III & - & - & $0.009(3.1,1.3$ to 7.2$)$ \\
\hline Sustained ventricular tachycardia & - & - & $0.013(3.9,1.3$ to 11.4$)$ \\
\hline \multicolumn{4}{|l|}{ Variables examined } \\
\hline Sex & Previous palliation, once & Follow up haemoglobin & Follow up atrioventricular valve regurgitation \\
\hline Left ventricular morphology & Previous palliation, twice & Follow up oxygen saturation & Prior sustained atrial flutter/fibrillation \\
\hline Isometric atrial appendages & Time from first to last palliation, years & Late cardiothoracic ratio & Prior sustained ventricular tachycardia \\
\hline Mean pulmonary artery pressure, $\mathrm{mm} \mathrm{Hg}$ & Pulmonary atrioventricular malformations & Subaortic stenosis & \\
\hline
\end{tabular}

*Cardiothoracic ratio was expressed in per cent (not fraction) for the purpose of data analysis.

be predictive of death (table 4 ). The degree of cyanosis and type of ventricular morphology were not predictive of arrhythmia or death.

\section{Discussion}

This study shows sustained palliation from cavopulmonary or aortopulmonary shunts, or both, among 50 adults with single ventricle physiology, who have not undergone a Fontan modification.

DEATH

Survival was $89.4 \%$ and $51.9 \%$ at 10 and 20 years, respectively, from the first UTCCCA clinic visit, with no difference between the two study groups. Not surprisingly, late mortality was substantial $(38 \%)$ in these adult patients with complex congenital heart disease, prohibitive of biventricular repair. However, there was no early operative mortality among the 17 patients who had a cavopulmonary or aortopulmonary palliation as adults, and survival curves from this study compare favourably to published Fontan series (reported 15 year survival, including early mortality, between $50-73 \%)^{23-28}$

The most common mode of death was sudden cardiac, presumably arrhythmic. This is in agreement with previous late outcome reports of isolated series of cavopulmonary ${ }^{2}$ or aortopulmonary shunts. ${ }^{29}$ Death from heart failure was also common in the cavopulmonary shunt group, presumably reflecting persistence of pre-existing ventricular dysfunction in some of these patients. In contrast, all patients with aortopulmonary shunts died suddenly. This difference in mode of death between the two groups, however, did not reach significance.

\section{ARRHYTHMIA}

Arrhythmia was a major cause of late morbidity for these patients. Both atrial and ventricular tachycardia were present in both groups with an ongoing attrition over time. Atrial flutter/fibrillation was more common among patients who underwent an aortopulmonary shunt; this group also had a larger heart at chest radiography. Atrial stretch, in response to volume overload, prolongs atrial refractoriness heterogeneously, making the atria vulnerable to induction of fibrillation. ${ }^{30} 31$ Chronic volume overload in our patients has almost certainly played a role in atrial arrhythmogenesis. This is particularly relevant as intra-atrial surgery was not usually involved to account for atrial tachyarrhythmia. In contrast, patients who undergo various Fontan modifications have a predisposition to late atrial arrhythmia, at least in part owing to incisions, suturing, and baffling within the atria; the higher prevalence of atrial arrhythmia in Fontan series ${ }^{32-35}$ (reported 10 year freedom from atrial flutter approximately $65 \%$ ), compared to our current series with a 10 year freedom from atrial tachyarrhythmia of $78 \%$, would support this hypothesis.

Multivariate analysis showed ventricular dysfunction to be an independent predictor of sustained ventricular tachycardia. Ventricular tachycardia, in turn, was predictive of death. Furthermore, there was an overlap between patients with atrial flutter/fibrillation and ventricular tachycardia, suggesting common haemodynamic substrates for atrial and ventricular arrhythmogenesis.

\section{VENTRICULAR FUNCTION}

Impaired ventricular function was seen in both groups. Patients who underwent a cavopulmonary shunt had worse ventricular function before the last palliation, compared to those who underwent aortopulmonary shunt(s) only. Ventricular dysfunction was indeed one of the reasons for a number of these patients to undergo a cavopulmonary shunt and not a Fontan modification at the last palliation. Despite this initial disadvantage, the degree of ventricular dysfunction at latest follow up was less in the cavopulmonary versus the aortopulmonary shunt group. Our data suggest that relative ventricular volume off loading, following construction of a cavopulmonary shunt, conveys a beneficial long term effect on ventricular function for these patients. In contrast, patients who underwent aortopulmonary shunts only and submitted to chronic, excessive volume overload exhibited a distinct decline in ventricular function with time.

Transplantation has been proposed as the last palliative source for patients with single ventricle physiology. ${ }^{14}$ Two of our patients with failing systemic ventricles from each group were referred for transplantation. Three received a heart; two of them are currently enjoying NYHA class I status, whereas one died intraoperatively from myocardial standstill of the donor heart. The fourth patient died on the waiting list, underscoring the continuing problem of shortage of donors. 
CYANOSIS AND COMPLICATIONS

Systemic oxygen saturation at latest follow up ranged from $71-91 \%$ (mean of $82 \%$ ). This degree of cyanosis was relatively well tolerated with no differences between the two groups. Most of the patients from our study had previous palliation(s), augmenting pulmonary blood flow to the contralateral lung before their definitive non-Fontan operation. Furthermore, over half of our patients had additional antegrade ventricular to pulmonary artery flow, through a non-disconnected pulmonary trunk, contributing to a "balanced" pulmonary circulation. ${ }^{18}{ }^{36}$ Cyanosis was not an independent predictor of death or arrhythmia.

Five patients with a classic Glenn shunt underwent further augmentation of pulmonary blood flow with a surgically constructed axillary arteriovenous fistula. This was followed by improved oxygen saturations in all. Patency of anastomoses or shunts was not assessed unless clinically indicated. Overall acceptable oxygen saturations, however, would suggest continuing functionality of the last palliation in this cohort of adult patients.

Pulmonary arteriovenous malformations were relatively uncommon in this series $(16 \%$ of patients with a classic Glenn shunt). As previously reported, ${ }^{37}$ they seemed to be present in patients who underwent an end to end cavopulmonary shunt at a relatively younger age. This would support the hypothesis proposed by Kawashima and colleagues ${ }^{38}$ that the putative substance in hepatic venous blood protecting against the formation of pulmonary arteriovenous fistulae can be transported to the lung through well developed bronchial collaterals in older patients.

Systemic thromboembolic events occurred in nine $(18 \%)$ patients; one of them died from a massive stroke. There was a relation between systemic thromboembolism and phlebotomies, ${ }^{39}$ suggesting that iron deficiency anaemia may have been involved. However, this is only speculative as ferritin values were not always available and, therefore, could not be included in the analysis. Our view, and the view of others, remains to restrict phlebotomies to cyanotic patients with hyperviscosity symptoms only, ${ }^{40}$ and supplement phlebotomised patients with iron for the risk of iron deficiency anaemia.

\section{PREDICTORS}

In our study, independent predictors of atrial flutter/fibrillation, sustained ventricular tachycardia, and death seemed to interrelate to each other, suggesting common pathophysiological substrates. Ventricular dysfunction was undoubtedly one of them. Construction of a cavopulmonary shunt at an earlier age, afterload reduction, and perhaps newer surgical techniques such as inferior vena cava to pulmonary artery anastomosis (allowing for somatic growth and systemic venous return redistribution) may provide longer myocardial protection for patients with single ventricle physiology, whether they undergo a complete Fontan procedure or not.
Many patients from this series could be considered as Fontan candidates, albeit at high risk. The clear advantage of a Fontan completion for them would be normal or near normal (for fenestrated Fontan) oxygen saturations, at the expense of an increased risk of early mortality, a chronic low cardiac output status, and the additional risk of late complications such as protein losing enteropathy. It has been argued that the assumption that patients with single ventricle physiology perform optimally with a normal ventricular volume may be incorrect. Vouhe and colleagues suggested that a volume of 1.5 times normal may be more appropriate for a single ventricle (personal communication). Of interest, Yeh and colleagues ${ }^{41}$ recently showed only a slight advantage on survival from converting patients from a cavopulmonary shunt to a Fontan modification in a large cohort from Toronto. Longer follow up data are required from earlier and recent Fontan series to substantiate the presumption of improved survival by normalising volume load in patients with single ventricle physiology. Our data suggest that a definitive palliation with a cavopulmonary shunt, combined with an additional source of pulmonary blood supply (aortopulmonary artery shunt to the contralateral lung and/or antegrade pulmonary artery flow) may provide a "balanced circulation", which is capable of very long term survival.

\section{LIMITATIONS}

This is not a natural/unnatural history study. Patients' enrollment was based on attendance at the UTCCCA specialised clinic with a potential for selection bias. Data regarding the denominator (for example, the total operated population) are lacking. Selection criteria for a cavopulmonary or aortopulmonary shunt at the last palliation were clinically determined. The absence of a Fontan control group limits the ability of the study to address directly whether a Fontan procedure should be performed in all patients with single ventricle physiology and no specific contraindications. Many of our patients were high risk Fontan candidates, however, and therefore inclusion of a Fontan group in the study would have been inappropriate. Furthermore, many patients from this study reflect the outcome of surgery performed in a different era. Nevertheless, we believe our cohort to be representative of a significant number of such patients currently in adulthood.

\section{CONCLUSIONS}

We conclude that cavopulmonary or aortopulmonary shunts, or both, provide sustained palliation and should be considered for selected patients with single ventricle physiology. Survival from this series compares favourably with published Fontan reports. Compared to aortopulmonary shunts, the cavopulmonary shunt conveyed a beneficial long term effect on ventricular function. Arrhythmia was a major cause of late morbidity in these patients, relating to both ventricular dysfunction and death. Onset of ventricular tachycardia is an ominous sign. 
We thank our colleagues from the Hospital for Sick Children, Toronto, for their continuing support of the UTCCCA
programme, and Dr Thorne for her helpful comments on the programme,

1 Glenn WWL. Circulatory bypass of the right side of the heart: shunt between superior vena cava and distal right pulmonary artery-report of clinical application. $N$ Engl $f$ Med 1958;259:117.

2 Kopf GS, Laks H, Stansel HC, et al. Thirty-year follow-up of superior vena cava-pulmonary artery (Glenn) shunts. $\mathscr{F}$ Thorac Cardiovasc Surg 1990;100:662-71.

3 Blalock A, Taussig HB. The surgical treatment of malformations of the heart in which there is pulmonary stenosis or atresia. FAMA 1945;128:189-202.

4 Potts WJ, Smith S, Gibson S. Anastomosis of the aorta to a pulmonary artery: certain types in congenital heart disease. p $A M A$ 1946;132:627-31.

5 Waterston DJ. Treatment of Fallot's tetralogy in children under 1 year of age. Rozhledy $v$ Chirurgii 1962;41:181-3.

6 Fontan F, Mounicot F, Baudet E, et al. "Correction" de

l'atresie tricuspidienne: raport de deux cas "corriqes" par l'atresie tricuspidienne: raport de deux cas "corriqes" par l'utilisation d'une technique chirucica

7 Pridjian AK, Mendelsohn AM, Lupinetti FM, et al. Usefulness of the bidirectional Glenn procedure as staged reconstruction for the functional single ventricle. Am f Cardiol 1993;71:959-62.

8 DiCarlo D, Williams WG, Freedom RM, et al. The role of cavo-pulmonary (Glenn) anastomosis in the palliative treatment of congenital heart disease. $\mathcal{F}$ Thorac Cardiovasc Surg 1982;83:437-42.

9 Calder AL, Chan N-S, Clarkson PM, et al. Progress of patients with pulmonary atresia after systemic to pulmonary arterial shunts. Ann Thorac Surg 1991;51:401-7.

10 de Leval MR, Kilner P, Gewillig M, et al. Total cavopulmonary connection: a logical alternative to atriopulmonary connection for complex Fontan operations. If Thorac connection for complex Font
Cardiovasc Surg 1988;96:682-95.

11 Kawashima Y, Kitamura S, Matsuda H, et al. Total cavopulmonary shunt operation in complex cardiac anomalies. $\mathcal{F}$ monary shunt operation in complex Card

12 Bridges ND, Lock JE, Castaneda A. Baffle fenestration with subsequent catheter closure. Modification of the Fontan operation for patients at increased risk. Circulation 1990;82: 1681-9.

13 Choussat A, Fontan F, Besse P, et al. Selection criteria for Fontan's procedure. In: Anderson RH, Shinebourne EA, eds. Paediatric cardiology. Edinburgh: Churchill Livingstone, 1977:559-66.

14 Vargas FJ, Mengo G, Gallo JP, et al. Bidirectional cavopulmonary shunt in patients with multiple risk factors. Ann Thorac Surg 1995;60:S558-62.

15 Hopkins RA, Armstrong BE, Serwer GA, et al. Physiological rationale for a bidirectional cavopulmonary shunt. F Thorac Cardiovasc Surg 1985;90:391-8.

16 DeLeon SY, Idriss FS, Ilbawi MN, et al. The role of the Glenn shunt in patients undergoing the Fontan operation. Glenn shunt in patients undergoing the For Cardiovasc Surg 1983;85:669-77.

17 McGoon MD, Fulton RE, Davis GD, et al. Systemic collateral and pulmonary artery stenosis in patients with congenital pulmonary valve atresia

18 Webber SA, Horvath P, LeBlanc JG, et al. Influence of competitive pulmonary blood flow on the bidirectional superio cavopulmonary shunt: a multi-institutional study. Circulation 1992;84(suppl II):II-279-86.

19 Simpson IA, de Belder MA, Kenny A, et al. How to quantitate valve regurgitation by echo Doppler techniques. $B$ Heart $\mathcal{7} 1995 ; 73: 1-9$.
20 Bergstralh EJ, Offord KP. Conditional probabilities used in calculating cohort expected survival. Technical report series, number 37. Rochester, Minnesota: Mayo Clinic Section of Medical Research Statistics, 1988.

21 Cox DR. Regression models and life tables. F R Stat Soc (B) 1972;34:187-220.

22 Glenn WWL, Fenn JE. Axillary arteriovenous fistula: a means of supplementing blood flow through a cavapulmonary artery shunt. Circulation 1972;46:1013-17.

23 de Brux JL, Zannini L, Binet JP, et al. Tricuspid atresia. Results of treatment in 115 children. $\mathcal{F}$ Thorac Cardiovasc Surg 1983;85:440-6.

24 Fontan F, Kirklin JW, Fernandez G, et al. Outcome after a "perfect" Fontan operation. Circulation 1990;81:1520-36.

25 Driscoll DJ, Offord KP, Feldt RH, et al. Five- to fifteen-year follow-up after Fontan operation. Circulation 1992;85:46996

26 Cetta F, Feldt RH, O'Leary PW, et al. Improved early morbidity and mortality after Fontan operation: the Mayo Clinic experience, 1987 to $1992 . \mathcal{F ~ A m ~ C o l l ~ C a r d i o l ~}$ 1996;28:480-6.

27 Gentles TL, Gauvreau K, Mayer JE, et al. Functional outcome after the Fontan operation: factors influencing late morbidity. F Thorac Cardiovasc Surg 1997;114:392403.

28 Bridges ND, Lock JE, Castaneda A. Baffle fenestration with subsequent catheter closure. Modification of the Fontan operation for patients at increased risk. Circulation 1990;82: 1681-9.

29 Crupi G, Alfieri O, Locatelli G, et al. Results of aorto-pulmonary anastomosis for tricuspid atresia with reduced pulmonary blood flow. Thorax 1979;34:290-3.

30 Satoh T, Zipes DP. Unequal atrial stretch increases dispersion of refractoriness conducive to developing atrial fibrillation. $\mathcal{F}$ Cardiovasc Electrophysiol 1996;7:833-42.

31 Morillo CA, Klein GJ, Jones DL, et al. Chronic rapid atrial pacing: structural, functional and electrophysiological characteristics of a new model of sustained atrial characteristics of a new model of

32 Fishberger SF, Wernovsky G, Gentles TL, et al. Factors that influence the development of atrial flutter after the Fontan operation. F Thorac Cardiovasc Surg 1997;113:80-6.

33 Balaji S, Gewellig M, Bull C, et al. Arrhythmias after the Fontan procedure: comparison of total cavopulmonary connection and atriopulmonary connection. Circulation 1991;84(suppl III):III-162-7.

34 Gewellig M, Wyse RK, de Leval MR, et al. Early and late arrhythmias after the Fontan operation: predisposing factors and clinical consequences. Br Heart f 1992;67:72-9.

35 Gelatt M, Hamilton RM, McCrindle BW, et al. Risk factors for atrial tachyarrhythmias after the Fontan operation. $f$ Am Coll Cardiol 1994;24:1735-32.

36 Uemura H, Yagihara T, Kawashima Y, et al. Use of bidirectional Glenn procedure in the presence of forward flow from the ventricles to the pulmonary arteries. Circulation 1995;92 (suppl II):II-228-32.

37 Kawashima Y, Matsuki O, Yagihara $\mathrm{T}$, et al. Total cavopulmonary shunt operation. Semin Thorac Cardiovasc Surg 1994;6:17-20.

38 Kawashima Y. Cavopulmonary shunt and pulmonary arteriovenous malformations. Ann Thorac Surg 1997;63: 930-2.

39 Ammash N, Warnes CA. Cerebrovascular events in adult patients with cyanotic congenital heart disease. $\mathcal{F}$ Am Coll Cardiol 1996;28:768-72.

40 Connelly MS, Webb GD, Somerville J, et al. Canadian consensus conference on adult congenital heart disease. Can $\mathcal{F}$ Cardiol 1998;14:395-452.

41 Yeh T, Williams WG, McCrindle BW, et al. Equivalent survival following cavopulmonary shunt: with or without the Fontan procedure. Eur f Cardiovasc Surg 1999;16:111-16. 